\title{
THE MANY FACES OF DEPRESSION IN PRIMARY CARE
}

\author{
Kathy Hegadoren ${ }^{1}$ Colleen Norris², Gerri Lasiuk ${ }^{3}$, Denise Guerreiro Vieira da Silva ${ }^{4}$, Kaitlin Chivers-Wilson ${ }^{5}$
}

\footnotetext{
${ }^{1}$ Registered Nursing. PhD. Canada Professor and Canada Research Chair in Stress Disorders in Women. Faculty of Nursing, University of Alberta. Alberta, Canada. E-mail: kathy.hegadoren@ualberta.ca

${ }^{2}$ Registered Nursing. PhD. Canada Professor and Canada Research Chair in Stress Disorders in Women. Faculty of Nursing, University of Alberta. Alberta, Canada. E-mail: colleen.norris@ualberta.ca.

${ }^{3}$ Registered Nursing. PhD. Canada Professor and Canada Research Chair in Stress Disorders in Women. Faculty of Nursing, University of Alberta. Alberta, Canada. E-mail: gerri.lasiuk@ualberta.ca

${ }^{4}$ Doutora em Enfermagem. Professor Associado do Departamento de Enfermagem e do Programa de Pós Graduação em Enfermagem da Universidade Federal de Santa Catarina. Pesquisadora do CNPq. Santa Catarina, Brasil. E-mail: denise@ ccs.ufsc.br

${ }^{5}$ Master's Students Science Psychiatry. University of Alberta. Alberta, Canada. E-mail: kaitlin@ualberta.ca
}

\begin{abstract}
Depression is a serious global health problem. It creates a huge economic burden on society and on families and has serious and pervasive health impacts on the individual and their families. Specialized psychiatric services are often scarce and thus the bulk of care delivery for depression has fallen to primary care providers, including advanced practice nurses and experienced nurses who work in under-serviced regions. These health professionals require advanced knowledge about the many faces that depression can display. This article reviews some of the faces of depression seen by primary care providers in their practices. Considering depression as a heterogeneous spectrum disorder requires attention to both the details of the clinical presentation, as well as contextual factors. Recommendations around engagement and potential interventions will also be discussed, in terms of the client population as well as for the practitioner who may be isolated by geography or discipline.
\end{abstract}

DESCRIPTORS: Depression. Primary health care. Mental health. Combined modality therapy.

\section{LAS MUCHAS CARAS DE LA DEPRESIÓN EN LA ATENCIÓN PRIMARIA}

RESUMEN: La depresión es un grave problema de salud mundial que crea una enorme carga económica sobre la sociedad y las familias, produciendo un grave y fuerte impacto en la salud del individuo y de sus familias. Los servicios psiquiátricos especializados a menudo son escasos y, por lo tanto, la mayor parte de la atención para la depresión ha quedado bajo la responsabilidad de los prestadores de atención primaria, incluyendo las enfermeras que trabajan en zonas remotas donde existen pocos servicios de salud. Esos profesionales de la salud requieren un conocimiento avanzado sobre las muchas caras que puede presentar la depresión. En el presente artículo se revisan algunos de los rostros de la depresión encontrados por los prestadores de atención primaria en sus prácticas. Teniendo en cuenta que la depresión es un trastorno de espectro heterogéneo, hay necesidad de prestar atención a los detalles de su presentación clínica, así como a los factores contextuales. También son discutidas recomendaciones sobre la participación de los prestadores de atención primaria y las potenciales intervenciones, en términos de la población a ser atendida, así como de los profesionales que pueden ser aislados por la geografía o por la temática.

DESCRIPTORES: Depresión. Atención primaria de salud. Salud mental. Terapia combinada.

\section{AS MUITAS FACES DA DEPRESSÃO NA ATENÇÃO PRIMÁRIA}

\begin{abstract}
RESUMO: A depressão é um grave problema de saúde global. Ela cria um enorme fardo econômico na sociedade e nas famílias e têm grave e penetrante impacto na saúde do indivíduo e de suas famílias. Serviços psiquiátricos especializados são muitas vezes escassos e, portanto, a maior parte da prestação de cuidados em depressão ficou sob a responsabilidade dos prestadores de cuidados primários, incluindo enfermeiras que trabalham em regiões isoladas onde há limitado atendimento em saúde. Estes profissionais da saúde requerem conhecimentos avançados sobre as muitas faces que a depressão pode apresentar. Este artigo revisa algumas das faces da depressão encontradas pelos prestadores de cuidados primários em suas práticas. Considerando que a depressão é um transtorno de espectro heterogêneo, há necessidade de atenção tanto para os detalhes de sua apresentação clínica, bem como dos fatores contextuais. Recomendações sobre o engajamento e as potenciais intervenções também são discutidas, em termos da população a ser atendida, bem como para os profissionais que podem estar isolados pela geografia ou pela disciplina.
\end{abstract}

DESCRITORES: Depressão. Atenção primária à saúde. Saúde mental. Terapia combinada. 


\section{INTRODUCTION}

Depression is a serious global health problem. The World Health Organization (WHO) predicts that by 2020 depression will be second only to ischemic heart disease in terms of global burden of disease. ${ }^{1}$ It creates a huge economic burden on society in terms of lost productivity and on families in terms of lost income. As well, it has serious and pervasive health impacts on the individual and their families. Specialized psychiatric services are often scarce and thus the bulk of care delivery for depression has fallen to primary care providers. These health professionals require advanced knowledge about the many faces that depression can display.

The term depression is used by the general public as well as health professionals to describe a spectrum of mood changes, varying in intensity, duration and characteristics. Primary care providers hear patients describe depression symptoms that may or may not meet full criteria for major depressive disorder, as detailed in the psychiatric classification system, Diagnostic and Statistical Manual of Mental Disorders- $4^{\text {th }}$ Edition - Text Revised (DSM-IV- TR) or other classification systems, such as the International Classification of Diseases (ICD 10). However, the symptoms often have significant impact on their social and occupational functioning, negatively affect their quality of life and prompt frequent interaction with the health care system..$^{2-3}$ In addition, there are subtypes of depression that differ in terms of specific symptoms or timing or intensity of symptoms. This makes identifying and treating depression a difficult challenge in primary care. Considering depression as a heterogeneous spectrum disorder is imperative. This approach requires attention to both the details of the clinical presentation, as well as contextual factors that should guide decisions regarding potential interventions.

Global shortages of Family Medicine practitioners and physician specialists have prompted the enormous interest in developing primary health care models. Time pressure has been identified by general practitioners as the biggest barrier to addressing psychological distress in their client population. ${ }^{4}$ Diverse models of primary care have arisen in response to differing national and regional health needs, resource availability and openness to exploit the full capacity of multidisciplinary health teams. ${ }^{5-6}$ In many parts of the world, nurses are increasingly taking on more independent responsibilities for assessment and ongoing management of chronic health problems within primary care settings. Nurse-led clinics are being staffed by nurse practitioners and advanced practice nurses, with access to consultative specialty services when required. ${ }^{7-9}$ In developing countries experienced nurses, physicians and community support workers are working in teams to provide primary care to underserviced populations. ${ }^{10}$ This shift in nursing practice necessitates a stronger knowledge foundation in mental health, especially in the more prevalent mood and anxiety disorders, than previously gained in undergraduate and graduate nursing programs ${ }^{11}$ It is well recognized that depression can be a chronic disease on its own, as well as be highly overrepresented in populations with other chronic medical conditions, like cardiovascular, metabolic, musculoskeletal and neuropsychiatric disorders. This article reviews some of the faces of depression seen by primary care providers in their practices. It is argued that primary health care models provide a framework for improving the detection and treatment of serious depression and anxiety symptoms in community-based practice settings. In this capacity, professional nurses need to understand that depression is a heterogeneous spectrum disorder that affects individuals across the life span and to apply rigour to the assessment of depression and anxiety. Recommendations around engagement and potential interventions will also be discussed, in terms of the client population as well as for the practitioner who may be isolated by geography or discipline.

\section{MAJOR DEPRESSIVE DISORDER}

The DSM-IV-TR ${ }^{12}$ characterizes Major Depressive Disorder (MDD) as having two core symptoms - consistent low mood and anhedonia, defined as the loss of pleasure from things that are usually pleasurable. At least five associated symptoms (e.g. loss of appetite, sleep disturbance, restlessness or psychomotor retardation, decreased energy, feelings of worthlessness and guilt and/or suicidal ideation) also need to be present. These symptoms must persist for at least two weeks and cause significant impairment of social, occupational and personal functioning. Some clinicians use the term clinical depression or unipolar depression rather than MDD, to differentiate this type of depression from bipolar depression, which is characterized by periods of depression and mania.

While lifetime prevalence rates for MDD suggest that it is a fairly common disorder, especially in women, these epidemiological data do not reflect the full impact of depressive symptoms. Only about one-third of depressed individuals seek health 
services for their symptoms, even if they recognize they are struggling. A significant proportion of primary care is related to patients who seek services for somatic complaints, have significant anxiety and depression symptoms, but not MDD..$^{13}$ While treatment guidelines are clear for the treatment of MDD, interventions for sub-threshold depressive symptoms require more contextual consideration.

\section{Depression and stress}

Serious overwhelming or chronic stress and depression are closely related; especially among women. ${ }^{14}$ Their declining ability to function day to day functioning generates feelings of shame, guilt, failure and powerlessness. Over time, these women can develop the characteristic depression profile. However, it must be noted that depression is not the only outcome of overwhelming or chronic stress. Other associated outcomes include acute stress disorder, posttraumatic stress disorder, chronic pain syndromes and autoimmune disorders such as chronic fatigue and fibromyalgia.

First episodes of depression are often related to a significant psychosocial stressor. Weiss and Post ${ }^{15}$ postulated that through a cascade of neurobiological changes that occurs during depression individuals may be at risk for developing reoccurrences of depression in the future triggered by less significant stressors. They termed this phenomenon kindling. This increased vulnerability may in part be mediated by changes in stress response systems, such as the hypothalamic-pituitaryadrenal axis ${ }^{16-18}$ or changes in key enzymes related to neurotransmitter function. ${ }^{19}$ Although the exact mechanisms that underlie kindling as it relates to depression are unknown, epidemiological studies do support that the risk of future episodes increases with the number of previous episodes. ${ }^{20}$ Genetic and psychological factors and gender also contribute to overall risk of developing MDD. For primary care providers, these data underscore the importance of discussing past serious stressors and past as well as family history of MDD.

\section{Depression and gender}

It is widely recognized that lifetime prevalence rates of depression are almost double in women, compared to men. ${ }^{21}$ This gender bias is observed irrespective if whether the study was done in a clinical setting or a community sample or in developed or developing nations. That being said, it is also recognized that men often hide or deny their symptoms, are less likely to seek treatment and are more likely to self-medicate with alcohol. Thus the prevalence difference between men and women may be less that what is commonly reported.

There are many theories that attempt to explain the increased vulnerability for depression in women. Sociopolitical theories focus on women's roles in society and power differences between men and women. Psychological theories focus on gender and personality traits and concepts like locus of control, dependency and coping styles. Biological theories are supported by evidence that increased vulnerability is observed at times of hormone changes: puberty, postpartum and perimenopause. For example, epidemiological studies have found that the differences in prevalence rates of depression between men and women do not begin to emerge until early adolescence..$^{22}$ Bungay and colleagues ${ }^{23}$ looked at gender differences in depression symptoms (not prevalence rates of MDD) across time in a population of healthy men and women aged 30 to 65 . Very different patterns between males and females were observed, especially between men and women aged 45 and 50 . Women reported sharp increases in sleep problems, making decisions and self-confidence in perimenopause. However, a recent American study showed that low birth weight can also be a risk factor for depression in girls. ${ }^{24}$ In the study population ( $\mathrm{n}=1420$ children aged 9 to 15), more boys than girls were born with low birth weight and had more early developmental problems. At age 12, depression rates for girls with low birth weight were greater than $20 \%$, compared to less than $5 \%$ in girls with normal birth weights or to both groups of boys. This pattern of significantly increased rate in girls with low birth weight continued through ages 13 to 15 .

Kendler and colleagues ${ }^{25}$ used structural equation modeling to create a predictive model for depression in women. Eight of the nineteen key variables were related to stressors, supporting a strong relationship between stressors and depression in women. Others have reported on the strong relationship between social support and women's health and well being. ${ }^{26}$ Indeed, poor social support is a known risk factor for depression. The highest prevalence rate of depression among women is explained by the increased frequency of childhood sexual abuse experienced by girls. ${ }^{27}$

There is an urgent need to begin to integrate these theories and develop more gender specific etiological models of depression. These newer models could then be used to develop more tar- 
geted and novel interventions that truly reflect the broad contextualized gender differences in degree of risk and the clinical presentations.

\section{IMPORTANT SUBTYPES OF DEPRES- SION}

Other faces of depression include dysthymia and atypical depression. Dysthymia is characterized in the DSM-IV-TR ${ }^{12}$ as chronic subthreshold depression that lasts for months but with periods of full remission between such episodes. Another subtype of depression is atypical depression, so called for the reversed neurovegetative symptoms of increased sleep and appetite, usually focused specifically on carbohydrates. Both of these subtypes of depression are overrepresented in women compared to men.

A gender specific face of is Postpartum Depression (PPD). Similar to dysthymia and atypical depression, PPD is defined by the DSM-IV-TR ${ }^{12}$ as a Major Depressive Episode Specifier and can only be diagnosed if the full criteria for MDD are met within 4 weeks postpartum. However, much of the literature on this topic does not use such a restrictive definition. A cut-off score of 12 or greater in the most widely used scale, the Edinburgh Postnatal Depression Scale, has been commonly considered to represent PPD. ${ }^{28}$ PPD share many of the same characteristics of MDD, but also has some differences. More anxiety and mood lability are typical, as are specific ruminations about being a bad mother or inadvertently harming the baby. The epidemiology data also highlights some distinctions between PPD and MDD. For $60 \%$ of women with PPD, it will be their first episode, while MDD is typically diagnosed in mid to late adolescence. ${ }^{29}$ Up to $15 \%$ of women with PPD had antepartum symptoms, which further limits the clinical value of the DSM IV definition of PPD. ${ }^{30}$ More disturbing are data suggesting that only $50 \%$ of women with PPD seek treatment for their symptoms. Stigma, shame and guilt, breastfeeding issues and reluctance to be prescribed antidepressants are some of the reasons cited for this low rate of help seeking.

\section{Depression and age}

Women are not the only vulnerable population. One in five adolescents will experience depression and epidemiological data suggests that the rates of childhood depression are increasing faster than any other age group..$^{22}$ While up to $25 \%$ of the elderly report depression symptoms, the rates of MDD among seniors are actually lower than in adulthood. ${ }^{31}$ Rates of MDD are higher in specific subgroups of the elderly; those with chronic health problems, on multiple drug therapies, living in long term facilities or in abusive homes. In the elderly, however, subthreshold depression can be a serious health issue as it impacts on older persons day to day functioning and social interactions.

The rates of MDD in those with chronic health problems range between 40 to $80 \%$. Specific chronic problems that have been associated with high risk for depression include: (a) cardiovascular diseases such as post-myocardial infarction and coronary heart disease; (b) autoimmune illnesses such as multiple sclerosis, fibromyalgia and chronic fatigue syndromes; (c) neuropsychiatric disorders such as Parkinson's disease, Alzheimer's disease and cerebrovascular problems; and (d) metabolic disorders such as Type II diabetes. ${ }^{32-35}$ Chronic activation of the Hypothalamic-pituitary-adrenal HPA axis can lead to insulin resistance and over time increase the risk of Type II diabetes in vulnerable individuals. This highlights another close association between chronic stress and health problems.

Behaviors associated with depression symptoms can also reflect age-related differences. For example, children with depression often are impulsive, restless and demonstrate poor play and social skills. ${ }^{36}$ Care is needed to discriminate between childhood depression and attention deficit disorders. Adolescents with depression also show greater impulsivity, as well as more irritability, mood lability and decline in academic and social functioning. ${ }^{37-38}$ Adolescent impulsivity makes this group at greater risk for suicide and engaging in high risk behaviors (alcohol and drug use, promiscuity, reckless driving, criminal activity). As previously noted, there are gender differences in associated behaviors observed in adults with depression. Women have more anxiety symptoms, whereas men have more comorbid alcohol use disorders. In the elderly, there is often a decline in activities of daily living and cognitive impairment than can be confused with early Alzheimer's disease. Loss of friends or spouse is more common in the elderly and grieving must also be separated from depression.

\section{Depression and culture}

Although prevalence rates of depression are similar across countries, ${ }^{39}$ the responses and help seeking behaviors that accompany the symptoms differ across cultures and ethnic groups. Differences may be found in the interpretation of symptoms, the meaning attributed to the symptoms, 
the degree of stigma surrounding mental health issues, where populations seek services and the types of available social supports.

In summary, depression is a serious global health problem. The high prevalence requires primary care providers to assess their patients for depressive symptoms, especially those in high risk categories. The use of standardized tools may be one strategy that can support immediate clinical decision making, as well as provide data for ongoing service development. Careful attention is needed to recognize the diversity of clinical presentations related to depression. Health professionals need to be aware of the importance of contextual factors such as past serious stressors, age and gender in the heterogeneous spectrum of depressive illnesses. Depression is a complex disorder. An appreciation of the complexity is imperative to fully utilize the broad spectrum of interventions available to help an individual gain full remission of their symptoms.

\section{PRIMARY CARE MODELS}

Many definitions of primary care have been put forward, but all share the basic principles of being a first level of contact with the health system to promote health, prevent illness, care for common illnesses, and manage ongoing health problems. The original focus on phsyisicans as being the sole primary care providers has been replaced with broader application to other health professionals. Two examples that reflect the diversity of how primary care can be structured are primary care networks and more specifically for mental health, "shared care" models. Primary care networks in Canada typically involve salaried physicians working with nurse practitioners and other health care professionals within an urban sector. Many provide both primary care and antepartum and postpartum obstetrical services for low risk pregnancies. Some physicians working in these networks also deliver babies, while others involve an obstetrician at the latter stage of the pregnancy in preparation for delivery by the specialist. The shared care model was developed in response to the scarcity of psychiatrists and the recognition of the advantages of a consultative model for the ongoing care of the mentally ill. ${ }^{40}$ The model involves a psychiatrist who acts as a consultant and together with mental health therapists and family physicians coordinate the delivery of mental health care. The mental health therapists provide specific mental health therapies to individuals, as well as join in family physician visits related to mental health issues. ${ }^{41-44}$
Other models have been described, using paraprofessional mental health workers, ${ }^{45}$ care coaches ${ }^{46}$ and community advocates within health teams. ${ }^{10}$ Collaborative care has been shown to be superior to only physician care in depression outcomes. ${ }^{47}$

\section{Primary care treatment issues in depression}

As a primary care provider, there are two fundamental requirements that must guide practice. The first is engagement, which involves more than case identification. Engagement goes beyond assessing for the presence of MDD, and centers on two-way communication about the past and current contexts of an individual's life that may impact on physical and mental health. The second focuses on intervention that goes beyond prescribing appropriate drug therapies to make shared decisions about workable strategies to address the varied symptoms, in a gender- and age-sensitive manner.

\section{Assessment}

There is increasing recognition that screening for both depression and anxiety symptoms are required, especially in primary care where the clinical reality is that they usually coexist. ${ }^{48} \mathrm{~A}$ full health history is the starting point for assessing depression and anxiety symptoms. This includes a full physical and mental health assessment. There are a number of well validated standardized tools to screen for depression. ${ }^{49} \mathrm{~A}$ recent meta-analysis showed that screening tools were associated with increased recognition, if used with other engagement techniques. ${ }^{50-51}$ This is also true for anxiety symptoms and alcohol use patterns. There are also several physical health surveys that can be used to record somatic symptoms. The decision to incorporate standardized tools as components of the assessment process should be made by the primary care team as a whole. Important considerations include: population served, characteristics of the community served, severity of the mental health problems encountered, availability of resources to respond to the data collected and protocols to rapidly incorporate the data from the standardized instruments into the clinical assessment. An added benefit of incorporating standardized tools into the practice setting is that it provides better data from which to evaluate the services and to guide ongoing policy and program development.

\section{The context}

Just as important as a health history is a psychosocial history, including serious past and 
current stressors and perceptions about how long and in what ways the individual felt any stressors affected or is affecting their health. Other aspects of the contextual assessment include: the individual's priorities, a profile of typical alcohol and drug use pattern (both recreational drug use and overuse of prescription or over the counter medications), specific questions about violence experiences, in particular in intimate relationships and finally their available resources. These resources can be at the level of personal strengths, connections with family and friends and community connections for recreation or more formalized support services.

There are no standardized tools that are widely used to gather contextual information. Examples of tools related to stressful life events include the Social Readjustment Scale, ${ }^{52}$ the Adverse Childhood Events Scale ${ }^{53}$ and the Posttraumatic Stress Disorder (PTSD) Symptom Scale. ${ }^{54}$ Other scales have been developed that look at various factors related to contexts of individuals' lives and their response to their experiences, such as coping, resilience, perceptions of stress or daily hassles, quality of life measures and impact of illness measures. However, most of these are used more in research than in clinical practice settings. Primary care providers can address this by adopting a few "standard" open ended questions for use with all their population served. Examples include: "Are there things that have happened or are happening in your life that you think are affecting your health?", "What makes your symptoms worse?" and "Has these stress symptoms happened before and if so how did you manage them before?" Standard questions about quality of sleep, work, social and personal relationships and specific stress management strategies can help identify areas for further discussion. Demographic information sheets that include questions related to contextual factors can be filled in while the individual is waiting to be seen and be used as a tool to open up discussion about high priority concerns.

As mentioned previously, there is a close relationship between experiences of violence and depression, especially in women. While it is well recognized that women who experience domestic violence are reluctant to voluntarily disclose any information, implementing universal screening practices in Emergency Departments or other health service sites is challenging. ${ }^{55}$ Key elements to a successful universal screening program are availability of resources to respond to disclosures of violence and ongoing professional education.

\section{Treatment of depression and anxiety}

Despite improvement in available treatments, patients with depression often remain under-diagnosed and inappropriately treated. Only about $1 / 3$ of individuals who recognize they are depressed will seek health services for their symptoms.$^{56}$ In the United State of America, fewer than $50 \%$ of those who would likely meet criteria for MDD receive any type of treatment for depression ${ }^{57}$ and only about $25 \%$ receive treatment according to published clinical guidelines. ${ }^{58}$

\section{Pharmacotherapeutic considerations}

There are several published clinical guidelines available to support treatment decision making by health care professionals. ${ }^{59}$ Antidepressants, particularly the Serotonin Selective Reuptake Inhibitors (SSRIs) are recommended as first line treatment for mood and anxiety disorders. However, these guidelines have significant limitations. They provide only limited direction related to the complexity and diversity of sociopolitical contexts. Gender is poorly addressed, as is pharmacoeconomics, issues related to access to health services and cultural views on psychotropic medication use.

It is imperative in primary care that decisions regarding the use of antidepressants must be a shared well informed decision between the patient and the primary care team or single provider. ${ }^{60}$ This can be very challenging, especially when the patient does not meet full criteria for MDD. It is helpful to put primary emphasis on the impact of symptoms on functioning in all spheres of life relevant to that person and on the persistence of the symptoms. Other considerations include what antidepressants are available, the cost of the drug regime, availability of follow up resources, age and pregnancy or postpartum. Specific subtypes of depression may require an alternative drug therapy regime to SSRIs. ${ }^{61}$ The age of the patient is also important in the choice of antidepressant. For example, the tricyclic antidepressant class is a poor choice for adolescents due to their potential lethality in overdose and for the elderly due to potential cardiovascular side effects. ${ }^{62}$ The SSRIs are considered to be first line therapy for depression as they have both antidepressant and anti-anxiety properties. However, the side effect profile related to weight gain and interference with sexual performance limit some of their use.

It must also be remembered that up to $1 / 3$ of patients fail to respond to any given antidepressant. Risk factors for poor treatment response to 
antidepressant therapy and a more chronic course of depressive illness include: multiple psychosocial issues, lower social support, significant alcohol or recreational drug use, violence, significant anxiety, chronic symptoms and multiple episodes. ${ }^{63}$ With an illness characterized by hopelessness, having a poor response to drug therapy can be devastating. Thus, it is important to discuss this prior to initiation of therapy, as well as the effects of the drug on each of their symptoms and perhaps even some sense of timeline (i.e. which symptoms are often the first to show improvement), what are serious side effects and what to do about them, the risk of withdrawal syndrome with abrupt cessation of therapy and the expected duration of therapy.

There are many alternative drug therapies, augmentation or adjuncts to antidepressants that have been considered. Herbal preparations and teas are very common. St John's Wart has been the most studied of the herbal preparations. ${ }^{64-65}$ Although the exact pharmacological properties have not been elucidated, it is a very common self medication for mild to moderate depression symptoms. Serious drug-drug interactions have been reported with St John's Wart and thus patients who are on drugs for other heath problems should be warned not to try this treatment. ${ }^{66}$ Both estrogen and progesterone have been used in the treatment of depression, especially for postpartum depression and perimenopausal depression symptoms. While some women do respond to these hormone therapies, clinical trials have failed to demonstrate strong efficacy as a single drug therapy for depression. ${ }^{67-69}$ The use of short term benzodiazepines for significant anxiety can be considered. However, the use of multi-drug therapies with such drugs as atypical antipsychotics or with mood stabilizers should only be considered in consult with a psychiatrist.

\section{Non-drug related therapies}

There is strong evidence that specific psychotherapies like Cognitive Behavioral Therapy (CBT) and interpersonal therapy are efficacious in the treatment of depression across the life span. ${ }^{70-71}$ The limitations to these therapies are the availability of psychotherapists with these specific skills and cost. Those living outside major urban centers have even less access to these specific therapies. Although there is less research evidence to demonstrate efficacy, there are a wide range of individual strategies that can be used alone for mild symptoms or as adjuncts to drug therapies in more severe cases of MDD. Workbooks that incorporate principles of $\mathrm{CBT}$, mindfulness training, brief focused therapy and mind-body techniques like yoga, meditation and relaxation tapes can all be used as tools to support recovery. Web-based learning modules and e-workbooks has been showed to be helpful with individual or small groups of patients. ${ }^{72} \mathrm{~A}$ recent meta-analysis to guided self-help in primary care mental health highlighted a number of themes associated with treatment outcomes. ${ }^{73}$ There is also an important role for exercise and nutrition. Strategies to improve the quality of sleep, such as decreasing caffeine, eating dinner earlier in the evening, decreasing evening alcohol intake and developing a calming pre-bed routine can be instrumental in feeling better able to manage the next day.

There is a very important role for social support in the treatment of depression, especially for women. ${ }^{74}$ This support can come in many forms. Professionally run group therapies focusing on loss, communication, general support or more formal ideologies can be therapeutic. Self-help groups can create a peer group that share workable strategies. Advocacy groups can lobby for more resources. Less directly focused on mental health but potentially powerful adjuncts are community social support networks (community leagues, community schools, drop in centers in community halls or recreational centers,) and community activities. These can include public speaking groups, craft groups, exercise groups and volunteering at community functions. Faith-based groups can also provide essential supports towards recovery.

In summary, there is strong evidence for the use of antidepressant drugs in the treatment of MDD and milder forms of depression that have pervasive impacts on individual functioning. The duration of treatment is dependent on individual response to drug therapy and past and current contextual factors. The need to augment antidepressant drug regimes with non-pharmacological interventions is likely far more common than is suggested by health professionals. Starting with an individualized inventory of available resources gained from the health history can help health professionals recognize who is at increased risk of poor treatment response and who needs consultation to mental health agencies or private practitioners.

\section{Care for the caregiver}

Primary care providers are not immune to chronic stress, in particular those that work alone or in isolated geographic settings. Limited health re- 
sources and daily interactions with highly stressed patients with limited personal resources can take their toll. Thus, it is essential for nurses who work within the various primary care models from nurseled clinics to isolated regions of the world to create novel personal strategies and professional support networks. Electronic technologies may be a good source. The computer is not only a tool to passively search for updated research data and clinical guidelines. There are many interactive psychoeducational and professional sites that can augment face to face discussions with other primary care nurse providers. Ongoing connection with academic nursing institutions is one strategy. Electronic communities of practice can also be established. The old concept of a "pen pal" can be recreated as a small group of nurse colleagues who use electronic methods via email, webcam and videoconferencing to gain professional support and mentorship. Some work in this area has already begun. The WHO has initiated a Community of Mental Health Practice as part of a global strategy to improve mental health care.

\section{CONCLUSION}

Depression is a serious global health problem. In many countries, the identification and treatment has shifted to primary care settings. Emerging primary care models depend heavily on nurses to provide independent care services. Thus, nurses who work within these care models have to have advanced knowledge of depression and anxiety symptoms and their impact on comorbid medical conditions across the age span. They need to recognize depression as a heterogeneous spectrum disorder with differing clinical presentations, longitudinal course and required intervention strategies. These nurses must also be confident in their assessment skills, such that they actively engage their client population, rather than expect clients to spontaneously disclose serious symptoms of depression and anxiety. With sufficient training and commitment to providing a high standard of primary care, nurses can make significant contributions to improving integrated health care around the world.

\section{REFERENCES}

1. World Health Organization. World Health Report 2001 [on line]. [acessed 2008 Jul 14]. Available at: http://www.who.int/en/

2. Vedsted $P$, Christensen MB. Frequent attenders in general practice care: a literature review with special reference to methodological consideratoins. Public Health. 2005 Feb; 119(2):118-37.
3. Smits FT, Wittkampf KA, Schene AH, Bindels PJ, Van Weert HC. Interventions on frequent attenders in primary care: a systematic literature review. Scand J Prim Health Care. 2008; 26(2):111-6.

4. Hutton C, Gunn J. Do longer consultations improve the management of psychological problems in genreral practice? A systematic literature review [on line]. 2007[acessed 2008 Jul 14]. Available at http:/ / www.biomedcentral.com/1472-6963/7/271

5. Naccarella L, Southern D, Furler J, Scott A, Prosser L, Young D, et al. Reforming primary care in Australia: a narrative review of the evidence from five comparator countries. Aust J Public Health. 2007 Aug; 13(2):38-45.

6. Rubin CD. The primary care of Alzheimer disease. Am J Med Sci. 2006 Dec; 332(6):314-33.

7. Courtney M, Carey N. Nurse-led care in dermatology: a review of the literature. Br J Dermatol. 2006 Jan; 154(1):1-6.

8. Courtney M, Carey N. The impact and effectiveness of nurse-led care in the management of acute and chronic pain. J Clin Nurs. 2008 Aug; 17(15):2001-3.

9. Laurant M, Reeves D, Hermens R, Braspenning J, Grol R, Sibbald B. Substitution of doctors by nurses in primary care. Cochrane Database of Systematic Reviews 2004, Issue 4. Art. No.: CD001271.

10. Abas M, Lovemore-Mbengeranwa O, SimmonsChagwedera IV, Maramba P, Broadhead J. Primary care services for depression in Harare, Zimbabwe. Harv Rev Psychiatry. 2003 May-Jun; 11(3):157-65.

11. Jolnierek CD. Mental health policy and integrated care: global perspectives. J Psychiatr Ment Health Nurs. 2008 Sep; 15(7):562-8.

12. American Psychiatric Association. Diagnostic and statistical manual of mental disorders. Revised $4^{\text {th }}$ ed. Washington(US): APA; 2003.

13. Croghan TW, Schoenbaum MS, Sherbourne CD, Koegel C. A framework to improve the quality of treatment for depression in primary care. Psychiatric Serv. 2006 May; 57(5): 623-30.

14. Herman J. Trauma and Recovery: The aftermath of violence - from domestic abuse to political terror. New York (US): Basic Books; 1997.

15. Weiss SR, Post RM. Caveats in the use of the kindling model of affective disorders. Toxicol Ind Health. 1994 Jul-Oct; 10(4-5):421-47.

16. Gutman DA, Gutman AF, Owens M J, Nemeroff CB. Stress neurobiology and corticotrophin-releasing factor. [on line]. Psychiatric Times. 2006 Sep; 23(9). [acessed 2008 July 16], Available at http://find. galegroup.com.login.ezproxy.library.ualberta.ca

17. Holsboer F, Muller OA, Doerr HG, Sippell WG, Stalla GK, Gerken A, etal. ACTH and multisteroid responses to corticotrophin-releasing factor in depressive illness: Relationship to multisteroid responses after ACTH stimulation and dexamethasone suppression. Psychoneuroendocrinology, 1984; 9(2):147-60. 
18. Nemeroff CB, Owens MJ, Bissette G, Andorn AC, Stanley M. Reduced corticotrophin releasing factor binding sites in the frontal cortex of suicide victims. Arch Gen Psychiatry. 1988 Jun; 45(6):577-9.

19. Meyer J. Brain monoamine oxidase A binding in major depressive disorder and its implications for striatal dopamine dysregulation. Int J Neuropsychopharmacol. 2008 Jul; 11(Suppl 1):70.

20. Frank E, Thase ME. Natural history and preventative treatment of recurrent mood disorders. Annu Rev Med. 1999; 50:453-68.

21. Kessler RC. Epidemiology of women and depression. J Affect Disord. 2003 Mar; 74(1): 5-13.

22. Spady DW, Schopflocher DP, Svenson LW, Thompson AH. Prevalence of mental disorders in children living in Alberta, Canada, as determined from physician billing data. Arch Pediatr Adolesc Med. 2001 Oct; 155(10):1153-9.

23. Bungay GT, Vessey MP, McPherson CK. Study of symptoms in middle life with special reference to the menopause. Br Med J. 1980 Jul; 281(6234):181-3.

24. Costello EJ, Worthman C, Erkanli A, Angold A. Prediction from low birth weight to female adolescent depression. Arch Gen Psychiatry.2007 Mar; 64(3):338-44.

25. Kendler SK, Gardner CO, Prescott CA. Toward a comprehensive developmental model for major depression in women. Am J Psychiatry. 2002 Jul; 159(7):1133-45.

26. Chen DR, Chang LY, Yang ML. Gender-specific responses to social determinants associated with self-perceived health in Taiwan: a multilevel approach. Soc Sci Med. 2008 Nov; 67(10):1630-40.

27. Nolen-Hoeksema S. Sex Differences in Depression. Stanford (US): Stanford University Press, 1990.

28. Mitchell AJ, Coyne J. Screening for postnatal depression: barriers to success. BJOG. 2009 Jan; 116(1):11-4.

29. Halbreich U, Karkun S. Cross-cultural and social diversity of prevalence of postpartum depression and depressive symptoms. J Affect Disord. 2006 Apr; 91(2-3):97-111.

30. Wisner K, Logsdon M, Shanahan B. Web-based education for postpartum depression: conceptual development and impact. Arch Womens Ment Health. 2008 Dec;11(5-6):377-85

31. Steffens DC, Skoog I, Norton MC, Hart AK, Tschanz JT, Plassman BL. et al. Prevalence of depression and its treatment in an elderly population. Arch Gen Psychiatry. 2000 Jun; 57(6):601-7

32. Hegadoren KM. Assessment and treatment of depression: a review in high-risk populations. J Wound Ostomy Continence Nurs. 2004 Sep-Oct; 31(5):259-72.

33. Eaton WW. Epidemiological evidence on the comorbidity of depression and diabetes. J Psychosom Res. 2002 Oct; 53(4):903-6.

34. Wittchen HU, Lieb R, Wundrlich U, Schuster P. Comorbidity in primary care: presentation and consequences. J Clin Psychiatry. 1999; 60(Suppl 7):29-36.
35. Palinkas LA, Wingard DL, Barrett-Connor E. Chronic illness and depressive symptoms in the elderly: a population-based study. J Clin Epidemiol. 1990; 43(11):1131-41.

36. Luby JL, Belden AC. Clinical characteristics of bipolar vs. unipolar depression in preschool children: an empirical investigation. J Clin Psychiatry. 2008 Dec; 69(12):1960-9.

37. Marmorstein NR. Longitudinal associations between alochol problems and depressive symptoms: early adolescence through early adulthood. Alcohol Clin Exp Res. 2009 Jan;33(1):49-59.

38. Erdur-Baker O. Peer victimization, rumination, and problem solving as risk contributors to adolescents' depressive symptoms. J Psychol. 2009 Jan;143(1):78-90.

39. Weissman MM, Bland R, Joyce PR, Newman S, Wells JE, Wittchen HU. Sex-differences in rates of depression - cross-national perspectives. J Affect Disord. 1993 Oct-Nov; 29(2-3):77-84.

40. Kates N, Craven M, Bishop J, Clinton T, Kraftcheck D, LeClair K, et al. Shared mental health care in Canada. Prepared by a joint working group of the Canadian Psychiatric Association and the College of Family Physicians of Canada. Ottawa, (CA): Canadian Psychiatric Association; 1997.

41. Byng R, Norman I, Redfern S, Jones R. Exposing the key functions of a complex intervention for shared care in mental health: case study of a process evaluation. BMC Health Serv Res. 2008 Dec; 8:274.

42. Haggarty J, Haslam D, Houlding C. Clinical findings of a cluster randomised control pilot trial of a Canadian Shared Care service for those with chronic mental illness. Prim Care Community Psychiatr. 2008 Mar; 13(1):19-25.

43. Younès N, Hardy-Bayle MC, Falissard B, Kovess V, Gasquet I. Impact of shared mental health care in the general population on subjects' perceptions of mental health care and on mental health status. Soc Psychiatry Psychiatr Epidemiol. 2008 Feb; 43(2):113-20.

44. Samy DC, Hall P, Rounsevell J, Carr R. 'Shared Care Shared Dream': Model of shared care in rural Australia between mental health services and general practitioner. Aust J Rural Health. 2007 Feb; 15(1):35-40.

45. Farand P, Confue P, Byng R, Shaw S. Guided selfhelp supported by paraprofessional mental health worlkers:an uncontrolled before-after cohort study. Health Soc Care Community. 2009 Feb; 17(1):9-17.

46. Toney SD. Identifying and managing depression in women. J Manag Care Pharm. 2007 Nov; 13(9 Suppl A):S16-22.

47. Gilbody S, Bower P, Fletcher J, Richards D, Sutton A. Collaborative care for depression: a cumulative meta-analysis and review of longer-term outcomes. Arch Intern Med. 2006 Nov; 166(21):2314-21.

48. Jacobs KS. The diagnosis and management of depression and anxiety in primary care: the need for 
Hegadoren K, Norris C, Lasiuk G, Silva DGV, Chivers-Wilson K

a different framework. Postgrad Med J. 2006 Dec; 82(974):836-9.

49. Mitchell AJ, Coyne J. Do ultra-short screening instruments accurately detect depression in primary care? A pooled analysis and meta-analysis of 22 studies. Br J Gen Pract. 2007 Feb; 57(535):144-51.

50. Gilbody S, Sheldon T, House A. Screening and casefinding instruments for depression: a meta-analysis. CMAJ. 2008 Apr; 178(8):997-1003.

51. Zuckerbrot RA, Jensen PS. Improving recognition of adolescent depression in primary care. Arch Pediatr Adolesc Med. 2006 Jul; 160(7):694-704.

52. Holmes TH, Rahe RH. The Social Readjustment Rating Scale. J Psychosom Res. 1967 Aug; 11(2):213-8.

53. Feletti VJ, Anda RF, Nordenberg D, Williamson DF, Spitz AM, Edwards V, et al. Relationship of childhood abuse and household dysfunction to many of the leading causes of death in adults. The Adverse Childhood Experiences (ACE) Study. Am J Prev Med. 1998 May;14(4):245-58.

54. Foa EB, Meadows EA. Psychosocial treatments for posttraumatic stress disorder: a critical review. Annu Rev Psychol. 1997; 48:449-80.

55. Taket A, Wathen CN, Macmillan H. Should health professionals screen all women for domestic violence? PLoS Med. 2004 Oct; 1(1):e4.

56. Greenfield SF, Reizes JM, Muenz LR, Kopans B, Kozloff RC, Jacobs DG. Treatment for depression following the 1996 Natinal Depression Screening Day. Am J Psychiatry. 2000 Nov; 157(11):1867-9.

57. Young AS, Klap R, Sherbourne CD, Wells KB. The quality of care for depressive and anxiety disorders in the United States. Arch Gen Psychiatry. 2001 Jan; 58(1):55-61.

58. Druss BG, Miller CL, Rosenheck RA, Shih SC, Bost JE. Mental health care quality under managed care in the United States: a view from the Health Employer Data and Information Set (HEDIS). Am J Psychiatry. 2002 May; 159(5):860-2.

59. Magruder KM, Yeager DE. Mental health problems in primary care: progress in North America. Eur J Psychiat. 2007 Jan-Mar; 21(1):55-61.

60. Griffiths KM, Christensen H. Depression in primary health care: from evidence to policy. Med J Aust. 2008 Apr; 188(8 Suppl):S81-3.

61. Wijeratne C, Sachdev P. Treatment-resistant depression: critique of current approaches. Aust $\mathrm{N}$ Z J Psychiatry. 2008 Sep; 42(9):751-62.

62. Cheung AH, Juckerbrot RA, Jensen PS, Ghalib K, Laraque D, Stein RE, et al. Guidelines for Adolescent

Correspondence adressed: Kathy Hegadoren

Faculty of Nursing - University of Alberta

Room 4-130 Clinical Sciences Building

Edmonton, Alberta - Canada T6G 2G3

E-mail: Kathy.hegadoren@ualberta.ca
Depression in Primary Care (GLAD-PC): II. Treatment and ongoing management. Pediatrics. 2007 Nov; 120(5); e1313-26.

63. Gilchrist G, Gunn J. Observational studies of depression in primaty care:what do we know? BMC Family Practice [on line]. 2007 May [acessed 2008 Jul 14]; 8:28. Available from http://www. biomedcentral.com/1471-2296/8/28

64. McGarry H, Pirotta M, Hegarty K, Gunn J. General practitioners and St John's Wort: a question of regulaiton or knowledge? Complement Ther Med. 2007 Jun; 15(2):142-8.

65. Linde K, MulrowC, Berner M, Egger M. St. John's Wort for depression. [s.l.]: The Cochrane Library, 2006.

66. Hammerness P, Basch E, Ulbricht C, Barrette EP, Foppa I, Basch S, et al. St John's Wort: a systematic review of adverse effects and drug interactions for the consultation psychiatrist. Psychosomatics. 2003 Jul-Aug; 44(4):271-82.

67. Dennis CL, Ross LE, Herxheimer A. Oestrogens and progestins for preventing and treating postpartum depression. Cochrane Database of Systematic Reviews 2008, Issue 4. Art. No.: CD001690.

68. Heinrich $A B$, Wolf OT. Investigating the effects of estradiol or estradiol/progesterone treatment on mood, depressive symptoms, menopausal symptoms and subjective sleep quality in older healthy hysterectomized women: a questionnaire study. Neuropsychobiology. 2005; 52(1):17-23.

69. Yonkers KA. Special issues related to the treatment of depression in women. J Clin Psychiatry. 2003; 64 (Suppl 18):8-13.

70. RupkeSJ, Blecke D, Renfrow M. Cognitive therapy for depression. Am Fam Physician. 2006 Jan; 73(1):83-6.

71. Harrington R, Whittaker J, Showbridge P, Campbell F. Systematic review of efficacy of congitive behavioral therapies in childhood and adolescent depressive disorder. Br Med J 1998 May; 316: 1559-63.

72. Kaltenthaler E, Brazier J, De Nigris E, Tumur I, Ferriter M, Beverly C, et al. Computerized cognitive behavioral therapy for depression and anxiety update: a systematic review and economic evaluation. Health Technol Assess. 2006; 10(33):1-168.

73. Kahn N, Bower P, Rogers A. Guided self-help in primary care mental health. Br J Psychiatry. 2007 Sep; 191:206-11.

74. Leach LS, Christensen H, Mackinnon AJ, Windsor $\mathrm{TD}$, Butterworth P. Gender differences in depression and anxiety across the adult lifespan: the role of psychosocial mediators. Soc Psychiatry Psychiatr Epidemiol. 2008 Dec; 43(12):983-98.

Recebido em: 15 de junho de 2008 Aprovação final: 27 de fevereiro de 2009 